\title{
Simulation of saturated and unsaturated flow in karst systems at catchment scale using a double continuum approach
}

\author{
J. Kordilla ${ }^{1}$, M. Sauter ${ }^{1}$, T. Reimann ${ }^{2}$, and T. Geyer ${ }^{1}$ \\ ${ }^{1}$ Geoscientific Centre, University of Göttingen, Göttingen, Germany \\ ${ }^{2}$ Institute for Groundwater Management, TU Dresden, Dresden, Germany \\ Correspondence to: J. Kordilla (jkordil@gwdg.de) \\ Received: 16 January 2012 - Published in Hydrol. Earth Syst. Sci. Discuss.: 1 February 2012 \\ Revised: 25 September 2012 - Accepted: 5 October 2012 - Published: 30 October 2012
}

\begin{abstract}
The objective of this work is the simulation of saturated and unsaturated flow in a karstified aquifer using a double continuum approach. The HydroGeoSphere code (Therrien et al., 2006) is employed to simulate spring discharge with the Richards equations and van Genuchten parameters to represent flow in the (1) fractured matrix and (2) conduit continuum coupled by a linear exchange term. Rapid vertical small-scale flow processes in the unsaturated conduit continuum are accounted for by applying recharge boundary conditions at the bottom of the saturated model domain. An extensive sensitivity analysis is performed on single parameters as well as parameter combinations. The transient hydraulic response of the karst spring is strongly controlled by the matrix porosity as well as the van Genuchten parameters of the unsaturated matrix, which determine the head dependent inter-continuum water transfer when the conduits are draining the matrix. Sensitivities of parameter combinations partially reveal a non-linear dependence over the parameter space. This can be observed for parameters not belonging to the same continuum as well as combinations, which involve the exchange parameter, showing that results of the double continuum model may depict a certain degree of ambiguity. The application of van Genuchten parameters for simulation of unsaturated flow in karst systems is critically discussed.
\end{abstract}

\section{Introduction}

Discharge dynamics in karst aquifers are determined by superposition of several effects: (1) water infiltration into soil, (2) water percolation through the unsaturated zone,
(3) groundwater flow in highly conductive karst conduits and interaction with (4) groundwater flow in the low-conductive fissured and fractured rock matrix. These different effects, without even having considered the variability of precipitation and evapotranspiration, are a result of the particular properties of the individual compartments: soil-epikarstic zone, vadose zone, and phreatic zone. Each of these compartments is, in turn, characterized by two coupled flow systems: a highly permeable one with low storage and a less permeable one with high storage. Therefore, different individual (rapid, slow) flow components with characteristic temporal distributions are induced. Accordingly, the final spring discharge is then a function of the individual flow contributions of each of these compartments (Smart and Hobbs, 1986), which makes the inverse analysis of spring discharge a major challenge, requiring elaborate modeling tools and a large spectrum of data to constrain the model. The simulation of coupled saturated and unsaturated flow is still a challenge in hydrogeology in particular in fractured (Therrien and Sudicky, 1996) and karstified systems (Reimann et al., 2011a). This is predominantly a result of the data scarcity respecting the hydraulic parameter field of real karst systems. Therefore, flow in karst systems is often simulated with lumped parameter modeling approaches, which translate precipitation signals to discharge hydrographs by applying simple transfer functions (Dreiss, 1989). Generally, this type of approach is appropriate for situations in which predicted system states are expected to range between already observed events. The simulation of natural karst systems with distributed parameter models is reported only in a few studies (e.g. Jeannin, 2001; Hill and Polyak, 2010). However, distributive modeling approaches incorporate flow 
laws and, therefore, are adequate for the process based simulation of karst hydraulics (e.g. Birk et al., 2006; Reimann et al., 2011b) and transport problems (e.g. Dreybrodt et al., 2005; Birk et al., 2005). Teutsch and Sauter (1991) demonstrate how far the different mathematical model approaches are suitable for different types of problems (flow, transport, regional, local). An approach that takes into account the limited information about aquifer geometry and still allows for the simulation of the dynamics of the karst system at an event basis, i.e. considers the dual flow behavior of karst systems is the double continuum approach (e.g. Teutsch and Sauter, 1991; Sauter et al., 2006). The approach was introduced by Barenblatt et al. (1960) and applied for simulation of karst hydraulics on catchment scale by Teutsch (1988) and Sauter (1992). It yields equations for simulation of slow and diffuse flow in the fissured matrix and the discrete rapid underground drainage by solution conduits in karst systems. Here, we want to assess the relative importance of individual factors and parameter combinations on the discharge behavior of a karst spring without detailed knowledge about the hydraulic parameter field of an aquifer system. This type of information is of major importance to focus characterization efforts in catchment based karst studies. Furthermore, the importance of infiltration dynamics, i.e. the temporal distribution of the rapid and the slow flow component on the discharge dynamics is to be determined. We employ the integrated saturated-unsaturated double-continuum approach HydroGeoSphere (Therrien et al., 2006) to simulate recharge and discharge dynamics in a karst aquifer with a thick unsaturated zone. Flow simulations are based on the Richards equation and respective parameters are described via the van Genuchten parametric model. Given that the van Genuchten parameters have been developed for porous media on REV scales, parameters obtained for the large scale conduit system are pure calibration parameters without physical meaning in nature. Furthermore, the Richards equation is not able to express the highly nonlinear flow regime observed in unsaturated fractured rocks, for example, rivulet flow (Dragila et al., 2004; Germann et al., 2007). The application and limitations of the approach for flow simulation in karst systems are discussed. A comprehensive parameter study was conducted in order to elucidate sensitive and important model parameters as well as parameter dependencies, and to reduce the model ambiguity to assist in focused karst characterization.

\section{Methods}

\subsection{Modeling approach}

The application of the double-continuum approach requires two sets of flow equations, one for the matrix (primary) and one for the conduit (secondary) continuum, solved consecutively at the same node and coupled with an exchange term that defines the hydraulic interface and controls the inter- continuum exchange flow. The applied HydroGeoSphere model (Therrien et al., 2006) is a non-commercial code available to the interested user under http://hydrogeosphere.org/. The model has been extensively used for various studies involving dual porosities such as Mclaren et al. (2000), Rosenbom et al. (2009) and Schwartz et al. (2010). The governing equation in the applied model is the Richards equation (Richards, 1931), which is slightly modified to account for inter-continuum water exchange:

$$
\begin{aligned}
-\nabla w_{\mathrm{m}}\left(q_{\mathrm{m}}\right)+\Gamma_{\mathrm{ex}} \pm R_{\mathrm{m}} & =w_{\mathrm{m}} \frac{\partial}{\partial t}\left(\theta_{\mathrm{sm}} S_{\mathrm{wm}}\right) \\
-\nabla w_{\mathrm{c}}\left(q_{\mathrm{c}}\right)+\Gamma_{\mathrm{ex}} \pm R_{\mathrm{c}} & =w_{\mathrm{c}} \frac{\partial}{\partial t}\left(\theta_{\mathrm{sc}} S_{\mathrm{wc}}\right)
\end{aligned}
$$

where $w_{\mathrm{m}}$ and $w_{\mathrm{c}}$ are the volumetric fractions of each continuum of the total porosity, such that $w_{\mathrm{m}}=1.0-w_{\mathrm{c}} . S_{\mathrm{wm}}$ and $S_{\mathrm{wc}}$ are the water saturations of the respective continuum and $R_{\mathrm{m}}$ and $R_{\mathrm{c}}$ denote a volumetric fluid flux per unit volume (source/sink term) for each continuum. The saturated water content of the matrix and conduit system are assumed equal to the the effective matrix porosity $\theta_{\mathrm{sm}}$ and conduit porosity $\theta_{\mathrm{sc}}$ and are related to the water content of the matrix $\theta_{\mathrm{m}}$ and of the conduit $\theta_{\mathrm{c}}$ according to

$$
\begin{gathered}
\theta_{\mathrm{m}}=S_{\mathrm{wm}} \theta_{\mathrm{sm}} \\
\theta_{\mathrm{c}}=S_{\mathrm{wc}} \theta_{\mathrm{sc}} .
\end{gathered}
$$

The conduit and total porosity are given as

$\theta_{\text {total }}=\theta_{\mathrm{sm}}\left(1-w_{\mathrm{c}}\right)+\theta_{\mathrm{sc}} w_{\mathrm{c}}=\theta_{\mathrm{sm}}\left(w_{\mathrm{m}}\right)+\theta_{\mathrm{sc}} w_{\mathrm{c}}$,

i.e. the whole simulation domain consists of nodes with primary porosity $\theta_{\mathrm{sm}}$ with a volumetric fraction of $w_{\mathrm{m}}=1.0-$ $w_{\mathrm{c}}$ and secondary porosity $\theta_{\mathrm{sc}}$ with a volumetric fraction of $w_{\mathrm{c}}$. Given that the local conduit porosity is chosen to be 1.0 and that both continua cover the whole domain the overall conduit porosity can simply be evaluated as:

$\theta_{\mathrm{sc}} \triangleq \theta_{\mathrm{sc}(\text { local })} w_{\mathrm{c}}$

The fluxes $q_{\mathrm{m}}$ and $q_{\mathrm{c}}$ are obtained from

$$
\begin{aligned}
q_{\mathrm{m}} & =-K_{\mathrm{m}} k_{\mathrm{rm}} \nabla\left(\psi_{\mathrm{m}}+z\right) \\
q_{\mathrm{c}} & =-K_{\mathrm{c}} k_{\mathrm{rc}} \nabla\left(\psi_{\mathrm{c}}+z\right),
\end{aligned}
$$

where $K_{\mathrm{m}}$ and $K_{\mathrm{c}}$ denote hydraulic conductivity, $\psi_{\mathrm{m}}$ and $\psi_{\mathrm{c}}$ are the pressure heads in each continuum and $z$ is the elevation head.

In the unsaturated zone, the relative permeabilities $k_{\mathrm{rm}}$, $k_{\mathrm{rc}}$ and $k_{\mathrm{ri}}$ (interface) depend on the water saturation which in turn is related to the pressure head according to van Genuchten (1980):

$$
\begin{aligned}
S_{\mathrm{wm}} & =S_{\mathrm{wrm}}+\left(1-S_{\mathrm{wrm}}\right)\left[1+\left|\alpha_{\mathrm{m}} \psi_{\mathrm{m}}\right|^{n_{\mathrm{m}}}\right]^{-m_{\mathrm{m}}} \\
S_{\mathrm{wc}} & =S_{\mathrm{wrc}}+\left(1-S_{\mathrm{wrc}}\right)\left[1+\left|\alpha_{\mathrm{c}} \psi_{\mathrm{c}}\right|^{n_{\mathrm{c}}}\right]^{-m_{\mathrm{c}}} \\
S_{\mathrm{wi}} & =S_{\mathrm{wri}}+\left(1-S_{\mathrm{wri}}\right)\left[1+\left|\alpha_{i} \psi_{\mathrm{m}}\right|^{n_{i}}\right]^{-m_{i}}
\end{aligned}
$$


for $\psi<0$, where $S_{\mathrm{wrm}}, S_{\mathrm{wrc}}$ and $S_{\mathrm{wri}}$ are the residual saturations, $\alpha_{\mathrm{m}}, \alpha_{\mathrm{c}}$ and $\alpha_{i}$ denote the inverse air-entry pressure head, $n_{\mathrm{m}}, n_{\mathrm{c}}$ and $n_{i}$ are the pore-size distribution indices of each continuum and the interface. Note that the evaluation of the interface relative conductivity is based on the pressure head of the matrix. In the saturated zone where $\psi \geq 0$, the saturations are $S_{\mathrm{wm}}=S_{\mathrm{wc}}=S_{\mathrm{wi}}=1$. The relative permeability is given by

$$
\begin{aligned}
k_{\mathrm{rm}}\left(S_{\mathrm{wm}}\right) & =S_{\mathrm{em}}^{\left(l_{\mathrm{p}}\right)}\left[1-\left(1-S_{\mathrm{em}}^{1 / m_{\mathrm{m}}}\right)^{m_{\mathrm{m}}}\right]^{2} \\
k_{\mathrm{rc}}\left(S_{\mathrm{wc}}\right) & =S_{\mathrm{ec}}^{\left(l_{\mathrm{p}}\right)}\left[1-\left(1-S_{\mathrm{ec}}^{1 / m_{\mathrm{c}}}\right)^{m_{\mathrm{c}}}\right]^{2} \\
k_{\mathrm{ri}}\left(S_{\mathrm{wi}}\right) & =S_{\mathrm{ei}}^{\left(l_{\mathrm{p}}\right)}\left[1-\left(1-S_{\mathrm{ei}}^{1 / m_{i}}\right)^{m_{i}}\right]^{2}
\end{aligned}
$$

with $l_{\mathrm{p}}$ being the pore connectivity parameter (equals 0.5 after Mualem, 1976), $S_{\mathrm{e}}$ the effective saturation

$$
\begin{gathered}
S_{\mathrm{em}}=\frac{S_{\mathrm{wm}}-S_{\mathrm{wrm}}}{1-S_{\mathrm{wrm}}} \\
S_{\mathrm{ec}}=\frac{S_{\mathrm{wc}}-S_{\mathrm{wrc}}}{1-S_{\mathrm{wrc}}} \\
S_{\mathrm{ei}}=\frac{S_{\mathrm{wi}}-S_{\mathrm{wri}}}{1-S_{\mathrm{wri}}}
\end{gathered}
$$

and $m$ is defined as

$$
\begin{aligned}
& m_{\mathrm{m}}=1-\frac{1}{n_{\mathrm{m}}} \\
& m_{\mathrm{c}}=1-\frac{1}{n_{\mathrm{c}}} \\
& m_{i}=1-\frac{1}{n_{i}}
\end{aligned}
$$

for $n>1$. In the saturated zone, the storage terms on the right-hand side of Eqs. (1) and (2) are replaced by

$$
\begin{array}{r}
S_{\mathrm{wm}} S_{\mathrm{sm}} \frac{\partial \psi_{\mathrm{m}}}{\partial t}+\theta_{\mathrm{sm}} \frac{\partial S_{\mathrm{wm}}}{\partial t} \\
S_{\mathrm{wc}} S_{\mathrm{sc}} \frac{\partial \psi_{\mathrm{c}}}{\partial t}+\theta_{\mathrm{sc}} \frac{\partial S_{\mathrm{wc}}}{\partial t},
\end{array}
$$

where $S_{\mathrm{sm}}$ and $S_{\mathrm{sc}}$ are the specific storage coefficients. Water release by compaction of the porous medium is neglected in the unsaturated zone. The term $\Gamma_{\mathrm{ex}}$ in Eqs. (1) and (2) describes the volumetric fluid exchange rate per unit volume between primary and secondary continuum and is given as

$$
\Gamma_{\mathrm{ex}}=\alpha_{\mathrm{ex}} K_{\mathrm{i}} k_{\mathrm{ri}}\left(\psi_{\mathrm{c}}-\psi_{\mathrm{m}}\right),
$$

where $K_{\mathrm{i}}$ is the hydraulic conductivity of the interface (e.g. sediments) and $k_{\mathrm{ri}}$ the relative interface permeability (Barenblatt et al., 1960). The exchange parameter $\alpha_{\mathrm{ex}}$ is determined by calibration and defined as (Gerke and Van Genuchten, 1993):

$\alpha_{\mathrm{ex}}=\frac{\beta}{\alpha^{2}} \gamma_{\mathrm{w}}$, where $\beta$ is a geometry factor ( 3 for rectangular matrix blocks, 15 for spheres), $a$ is the distance between the center of a matrix block and the adjacent fracture or conduit and $\gamma_{\mathrm{w}}$ is an empirical coefficient usually set to 0.4 . As mentioned in the introduction the van Genuchten approach, adopted in HydroGeoSphere does not apply to fractured and karstified rock materials. The highly heterogeneous flow field and preferential flow paths associated with such media and the consequently greater size of an REV compared to porous media are rendering the parameter determination by laboratory experiments impractical. Still, the van Genuchten parameters reflect properties of an unsaturated porous material and can be considered as an adequate parameter set to describe transient infiltration processes if they are treated as calibration parameters in order to upscale from the Darcy-scale averaging volume to the field scale.

\subsection{Sensitivity analysis}

An extensive sensitivity analysis is performed to determine the influence of the calibrated parameters on the computed flow. The root-mean-square error (RMSE) is chosen to rate the accuracy of fit and calculate deviations from the calibrated model. The RMSE is defined as (Bamberg et al., 2007)

$\operatorname{RMSE}=\sqrt{\frac{1}{n} \sum_{i=1}^{n}\left(m_{i}-f_{i}\right)^{2}}$,

where $n$ is the total number of data points, $m_{i}$ denotes the simulated spring discharge derived by the sensitivity analyzes and $f_{i}$ is the calibrated model value. For sensitivity analyzes the RMSE has been evaluated using daily data and documented parameter ranges were employed if possible. However, for some variables, in particular the van Genuchten parameters for the unsaturated zone of hard rocks, only few data and estimates can be found in the literature, e.g. Weiss (1987), Sauter (1992), Contractor and Jenson (2000) and Roulier et al. (2006). Consequently, the sensitivity of these parameters was determined systematically to evaluate the degree of ambiguity of the model. Depending on field observations parameter ranges were varied on linear or log-scale. Parameter spaces were assigned to cover at least the reported values from field experiments. In order to provide a further quantitative comparison recession coefficients are given for one important recharge event during March $1988\left(\alpha_{1}\right)$ and the following recession until beginning of April $1988\left(\alpha_{2}\right)$. Due to the complex flow model it is likely that some parameters do not show a linear correlation and sometimes the simulated discharge curve is only influenced by specific parameter combinations. The final analysis of parameter sensitivity on an idealized example is subdivided into (1) insensitive parameters, (2) one sensitive parameter and (3) both parameters are sensitive (see Fig. 1, from left to right). In the latter case parameter A may be more sensitive for a certain 
range of parameter $B$. Given a constant parameter $B_{n}$ and $B_{n+d n}$ where $n$ denotes the parameter value and $d n$ a change in the parameter, the parameter combination is refered to as non-linear if the change in RMSE over the whole range of parameter $A$ is different for $B_{n}$ and $B_{n+d n}$, i.e. if

$f\left(A, B_{n}\right) \neq f\left(A, B_{n+d n}\right)$.

This case is particularly important if a properly calibrated model can be achieved for two different parameter combinations where at least one parameter is a pure calibration parameter, i.e. its range is difficult to estimate by field observations. Therefore, more than 1000 model runs were performed and the influence of parameter combinations on the simulated discharge curve analyzed.

\section{Case study}

\subsection{Description of the field site}

The HydroGeoSphere model is employed to simulate flow in the catchment area of the Gallusquelle spring from February 1988 to January 1990 . The Gallusquelle spring is situated in Southwest Germany on the Swabian Alb, a northeastsouthwest striking Jurassic carbonate plateau. The catchment area has been studied extensively by several authors including aquifer characterization (Birk et al., 2005; Sauter, 1992), speleology (Abel et al., 2002; Gwinner, 1976), and flow processes (Geyer et al., 2008). The size of the catchment is about $45 \mathrm{~km}^{2}$. It is delineated by a water divide in the northwest and the River Fehla in the northeast (see Fig. 2). In the south the catchment is bounded by the northeastern fault zone of the Hohenzollerngraben, which was found to be impermeable by tunneling works in the 1960s. After Sauter (1992) the base of the aquifer is formed by Kimmeridge marls (ki1). With a $70 \mathrm{~m}$ to $90 \mathrm{~m}$ thickness, this unit is rather consistent in the northwestern parts of the project area and consists of calcareous marls and occasional limestone intercalations. In the southeastern area, no borehole information about the lower boundary of the unit are available. The uppermost catchment is made up of a sequence of Kimmeridgian limestones (ki2-5) from which the majority is developed as algal-sponge facies and, therefore, belongs to the Unterer Massenkalk or Oberer Massenkalk. The largest part of the catchment comprises limestones belonging to the "Unterer Massenkalk" (ki2 and ki3). The whole Jurassic sequence dips southeast at an angle of 1.2 degrees.

\subsection{Geometry of the flow model}

Based on the geological model, a vertical two-dimensional model domain of the catchment area was set up. The length of the domain is $10 \mathrm{~km}$ with a vertical thickness of $225 \mathrm{~m}$. It reflects a cross section parallel to the direction of flow in the Gallusquelle catchment (see Fig. 2, lower figure). The model domain is represented by two continua reflecting flow in the low permeability fissured matrix (matrix continuum) and the highly permeable conduits (conduit continuum). The top of the model domain is set to 775 ma.s.l., which is an average elevation between ca. $910 \mathrm{ma}$ a.s.l. in the northwestern part of the catchment and ca. $640 \mathrm{ma}$ a.s.l. in the southeastern catchment and higher than the maximum groundwater head in the catchment. Every continuum is spatially discretized into 50 columns with a length of $200 \mathrm{~m}$ and a width of $1 \mathrm{~m}$ and 44 layers with a thickness of $5 \mathrm{~m}$.

\subsection{Boundary conditions}

The lateral sides of the matrix continuum and of the conduit continuum, as well as the top of the conduit continuum are defined as no flow boundaries (see Fig. 3). A constant head boundary is applied to the right side of the conduit continuum at $634 \mathrm{~m}$ a.s.l. to represent the spring and allow discharge. A specified flux boundary is set at the top of the matrix continuum to account for diffuse recharge. Daily data of total recharge was estimated by Geyer (2008) for the simulation period on the Gallusquelle catchment. The applied water balance approach accounts for canopy storage, snow storage and soil-moisture storage before water entering the bedrock. A second specified flux boundary is set on the bottom of the whole conduit continuum to add rapid recharge in the aquifer. The location of the boundary condition considers that the transit time of the rapid recharge component through the unsaturated zone is less than one day (Geyer et al., 2008) and, therefore, negligible with regard to the daily time steps. The simulation of rapid water percolation from the top of the conduit continuum to the groundwater surface is physically not possible with the van Genuchten approach, because it does not consider gravity driven flow processes like film and droplet flow. The initial head distribution for transient discharge simulations is computed with a steady state simulation. The applied total recharge for the simulation is $1.5 \mathrm{~mm} \mathrm{~d}^{-1}$, which corresponds to the average recharge across the catchment area during the year 1988. Ten percent of the total recharge is employed as rapid recharge component at the bottom of the conduit continuum. The amount is in the range of the rapid recharge component estimated by Sauter (1997) from event analysis using oxygen isotopes in precipitation and Gallusquelle spring water to differentiate between different flow components.

\subsection{Parameterization}

For the model calibration, known parameters are only varied within reasonable ranges that agree with actual field observations (Table 1). Unknown model parameters are investigated by an extensive sensitivity analysis. The specific storage coefficients for matrix and conduits are negligible since the aquifer is unconfined; hence, water released due to compaction in the saturated zone is irrelevant. As 

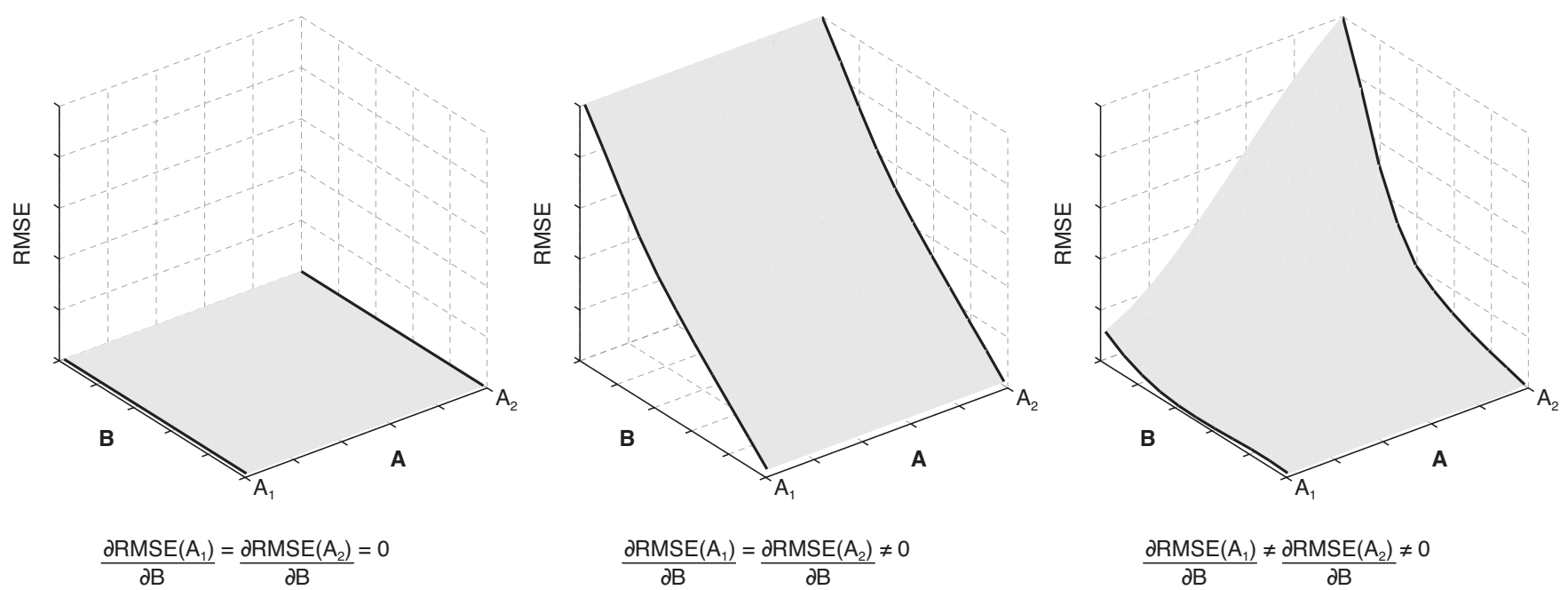

Fig. 1. Examples for inter-parameter dependencies. From left to right: (1) both parameters insensitive, (2) both parameters sensitive with linear dependency, (3) both parameters sensitive but non-linear dependency.

Table 1. Estimated values for the flow model derived from the model calibration and value ranges reported in the literature. Subscript $\mathrm{m}$ and c denote the matrix resp. the conduit continuum.

\begin{tabular}{lllll}
\hline Parameter & Unit & Value & Literature Values & Reference \\
\hline$K_{\mathrm{c}}$ & $\left(\mathrm{m} \mathrm{s}^{-1}\right)$ & 10.0 & $3.0-10.0$ & Sauter (1992) \\
$K_{\mathrm{m}}$ & $\left(\mathrm{m} \mathrm{s}^{-1}\right)$ & $2.9 \times 10^{-6}$ & $1.0 \times 10^{-6}-1.0 \times 10^{-4}$ & Sauter (1992) \\
$\theta_{\mathrm{sc}} \mathrm{a}$ & $(-)$ & 0.00023 & $0.00016-0.00064$ & Sauter (1992) \\
$\theta_{\mathrm{sm}}$ & $(-)$ & 0.042 & $0.007-0.025,>0.0-0.12$ & Sauter (1992); Weiss (1987) \\
$\alpha_{\mathrm{ex}}$ & $\left(\mathrm{m}^{-2}\right)$ & 1.0 & - & - \\
$Q$ & $(\%)$ & 90 & - & - \\
$\alpha_{\mathrm{m}}$ & $\left(\mathrm{m}^{-1}\right)$ & 0.0365 & $0.0365,0.0328-0.623$ & Roulier et al. (2006); Contractor and Jenson (2000) \\
$n_{\mathrm{m}}$ & $(-)$ & 1.83 & $1.83,0.01-3.0$ & Roulier et al. (2006); Contractor and Jenson (2000) \\
$S_{\mathrm{wrm}}$ & $(-)$ & 0.05 & $0.01-0.05$ & Contractor and Jenson (2000) \\
$\alpha_{\mathrm{c}}$ & $(-)$ & 5.1 & 5.1 & Roulier et al. (2006) \\
$n_{\mathrm{c}}$ & $(-)$ & 2.56 & 2.56 & Roulier et al. (2006) \\
$S_{\mathrm{wrc}}$ & $(-)$ & 0.0 & - & - \\
$k_{\mathrm{rminc}}$ & $(-)$ & 0.05 & - & - \\
\hline
\end{tabular}

${ }^{\text {a }}$ The local conduit continuum porosity is 1.0 i.e. $w_{\mathrm{c}} \theta_{\mathrm{sc}(\text { local })}=\theta_{\text {total }}-w_{\mathrm{m}} \theta_{\mathrm{sm}}$ implicitly gives the total conduit porosity such that $\theta_{\mathrm{sc}} \triangleq w_{\mathrm{c}} \theta_{\mathrm{sc}(\mathrm{local})}$. The total porosity is $\theta_{\text {total }}=0.0422$.

there are no documented values for the hydraulic properties of the interface available, the van Genuchten parameters $\alpha_{i}, n_{i}, S_{\mathrm{wri}}$ and the interface hydraulic conductivity $K_{i}$ were set to values equal to the surrounding fissured matrix. Accordingly, inter-continuum water exchange is solely controlled by adjusting the exchange parameter $\alpha_{\text {ex }}$. Model calibration is accomplished by fitting the observed and simulated discharge curves. Finally, the flow model contains 21 adjustable parameters for the fissured matrix and the conduit continuum.

\section{Results and discussion}

\subsection{Model calibration}

The calibrated model shows a good fit with most of the specific characteristics of the discharge hydrograph during the period between 16 February 1988 and 20 January 1990 (see Fig. 4). Please note that the discharge has been normalized to the catchment area $\left(45 \mathrm{~km}^{2}\right)$. Calibrated values for all varied parameters are comparable to values documented in the literature (Table 1). The observed discharge curve shows less sharp peaks and is smoother than the simulated curve. Sauter (1992) did get a comparable fit with a double continuum model for the saturated zone. The author did apply a function 

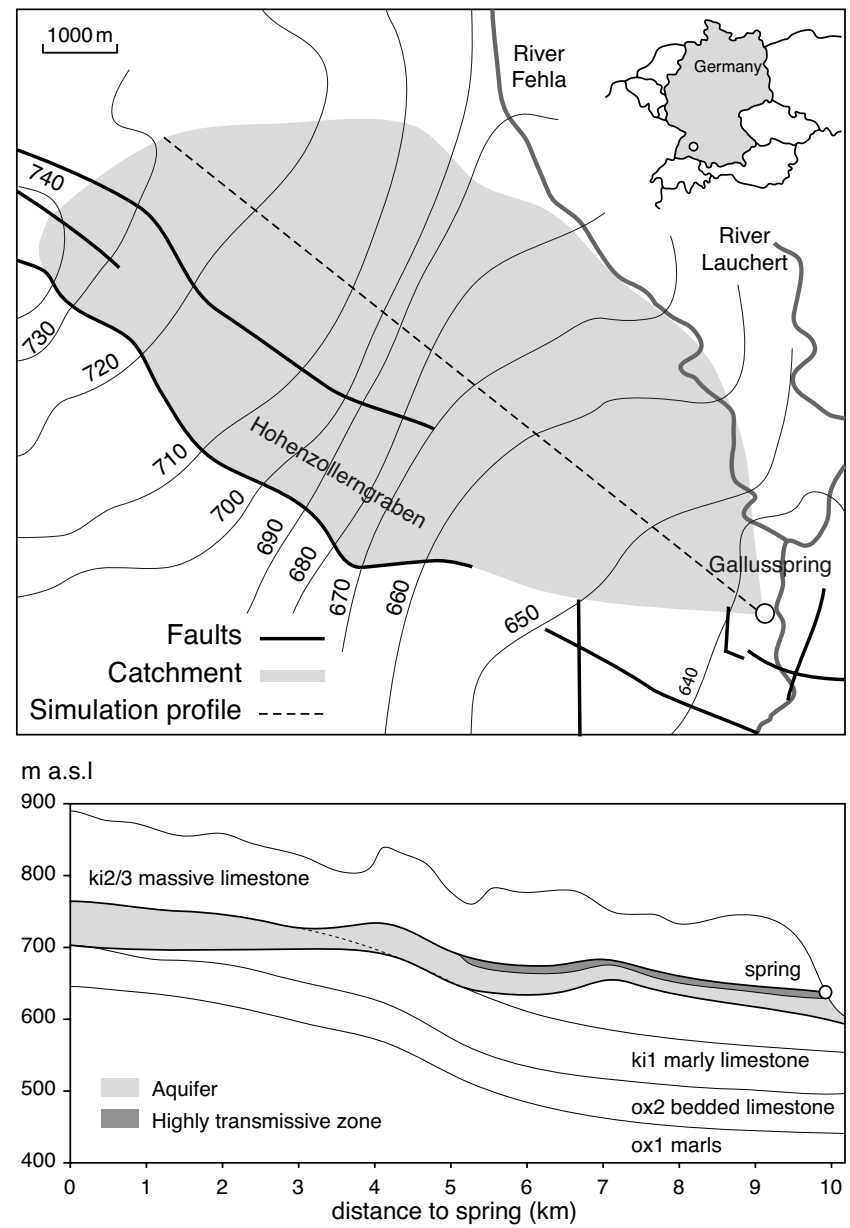

Fig. 2. Gallusquelle catchment and crosssection used for the simulation.

for the transfer of water from the soil zone to the groundwater surface, which is not necessary for our model.

During the time period investigated, two strong discharge events occurred caused by major snowmelts, which are referred to as first and second peak (see Fig. 4). The discharged water volume agrees well with the simulated data during the time period of the first peak. During the second discharge event (second peak) the simulated peak height is overestimated. It is not possible to change the relative peak height difference between the first and second peak with the available calibration parameters. The recession curve slopes after discharge events show a good fit, except during low flow conditions between July and October 1989. This behavior could be attributed to the simplified geometry of the numerical model, which does not include the documented slightly inclined aquifer base and the geometry of different karstified zones in the karst system. The hydraulic heads in the matrix continuum and the conduit continuum are nearly identical during the simulation period with a difference of a few centimeters. Above the water table the matrix saturation drops to
0.35 near the surface (see Fig. 5). Flow paths in the unsaturated matrix continuum and conduit continuum are slightly inclined towards the spring, whereas flow in the saturated zone is laterally oriented towards the outlet, i.e. the karst spring. The flow paths of the unsaturated matrix continuum, which would be expected to be vertical for such a large scale porous medium, are caused by the strong influence of the conduit continuum, which imposes a strong hydraulic gradient all over the matrix continuum. This behavior cannot be prevented unless the secondary continuum would be restricted to cover only the saturated zone. However, this is not an adequate solution considering the transient behavior of the system, i.e. the variation of water levels within both continua. The saturation in the conduit continuum is close to zero and has a very sharp transition along the water table. In this model, unsaturated flow in the conduits is also calibrated by the $k_{\text {rminc }}$ parameter (minimum relative permeability of the conduits). Without this parameter, the relative permeability of the conduit continuum is a function of the residual saturation, i.e. setting of $k_{\text {rminc }}$ simply overrides Eq. (13). This is the case for most of the unsaturated conduit continuum, where saturation declines very quickly (below 0.05) above the water table for the given van Genuchten parameters. Therefore, with the applied van Genuchten parameters only, water flow in the unsaturated conduit continuum is extremely small such that exchange from the matrix into the conduit system is nearly completely prevented and a proper model calibration is impossible due to numerical insufficiencies. However, Tokunaga and Wan (1997) showed that gravity driven film flow processes occur on unsaturated fracture walls, which contribute to water percolation along surfaces and may act as an interface from the conduit system to the matrix system, thus giving a physical meaning to the $k_{\text {rminc }}$ parameter. As the original van Genuchten model relies on a unimodal distribution of the pore space the hydraulic response of such flow processes cannot be expected to be resolved by the model. Attempts to refine the original van Genuchten approach and include hydraulic features of fractures into a continuum model have been made for example by Ross and Smettem (1993), Durner (1994) and Brouyère (2006) by constructing a continuous bi-modal retention curve.

An important role for the water exchange in the double continuum approach is the exchange parameter $\alpha_{\text {ex }}$. It determines the ability of water to move in and out of the conduit continuum and lumps geometrical and hydraulic properties of the karst matrix system. The surface-volume ratio, for example, is higher for a dendritic system than for a single conduit with the same conduit volume. The exchange parameter in the calibrated model is set to a high value such that it does not act as an additional barrier for water transfer between both continua and water transfer is mainly controlled by the hydraulic properties of the two continua. 


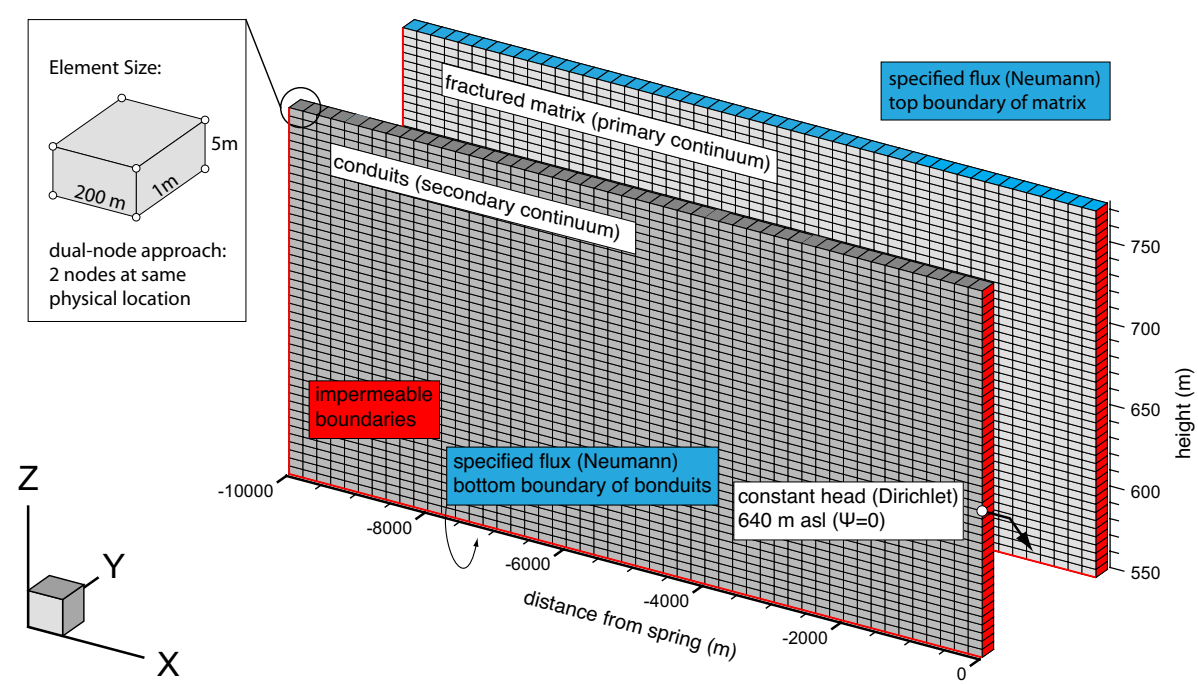

Fig. 3. Model grid of the two-dimensional model. A constant head boundary is applied at $640 \mathrm{~m}$ in the second continuum. Recharge is applied along the top boundary in both continua. Every node in the primary continuum has its counterpart in the secondary continuum at the same physical location.

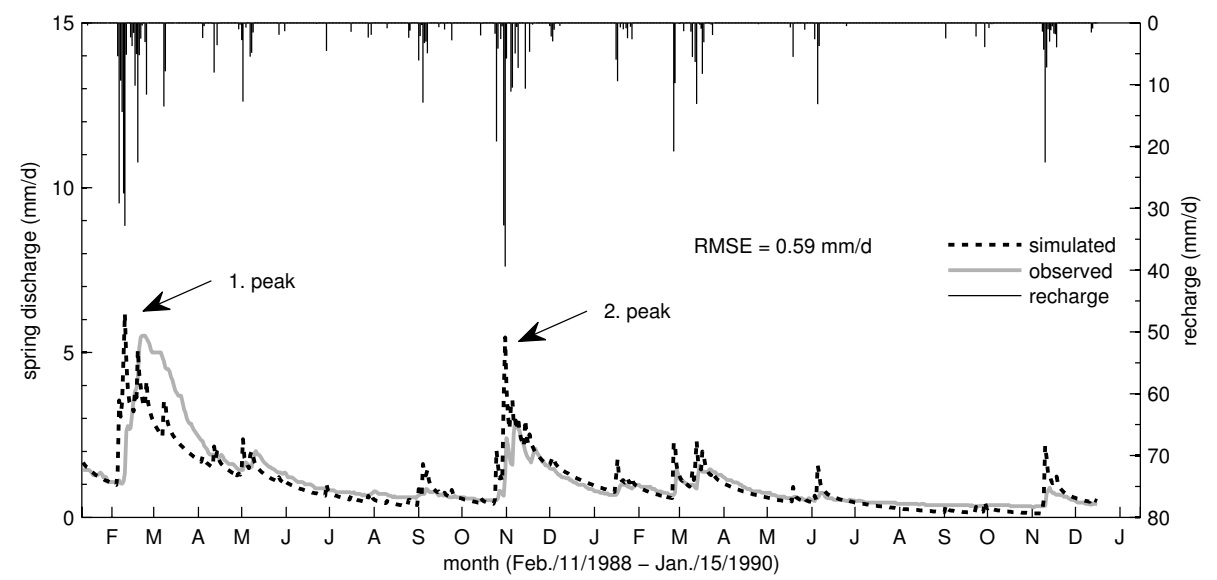

Fig. 4. The calibrated curve shows an acceptable fit. The secondary peak height is overestimated by the model. The first recharge event (first peak) reaches the spring too early. Recession curve slopes show a good overall correlation.

\section{Sensitivity analysis}

\subsection{Single variation of hydraulic parameters for saturated flow conditions}

Table 2 gives an overview of the recession coefficients and RMSE values obtained for the sensitive parameters. A parameter has been discarded as insensitive if the maximum RMSE is below $0.05 \mathrm{~mm} \mathrm{~d}^{-1}$. The recession coefficients have been measured at the first strong recharge event beginning in March $1988\left(\alpha_{1}\right)$ and during the low flow recession beginning in April $1988\left(\alpha_{2}\right)$. The calibrated values are $\alpha_{1}=0.23$ and $\alpha_{2}=0.03$, which is close to what has been reported by Sauter (1989) for a conduit dominated recession $(\alpha=0.25)$ for the same recharge event. Figure 6 (upper two graphs) shows the computed spring discharge for several model runs with varying hydraulic conductivity $K_{\mathrm{c}}$ and porosity $\theta_{\mathrm{c}}$ in the conduit continuum. These parameters strongly influence the simulated spring discharge. Figure 7 (upper two graphs) additionally shows the respective recession coefficients. An increased conduit conductivity $K_{\mathrm{c}}$ results in higher $\alpha_{1}$ recession coefficients and lower base flow levels indicated by the strong decrease of $\alpha_{2}$. A decreased conduit conductivity $K_{\mathrm{c}}$ favors a slow recession and decreases $\alpha_{1}$ to 0.06, which according to Sauter (1989) already indicates a mixed system (fractured matrix + conduits) response. Discharge peaks are broadened and the base flow is higher. In case the conduit drains the matrix system, an increase of $K_{\mathrm{c}}$ enhances the exchange process between matrix and conduits by decreasing the hydraulic gradient in the conduit continuum and consequently increasing the hydraulic 

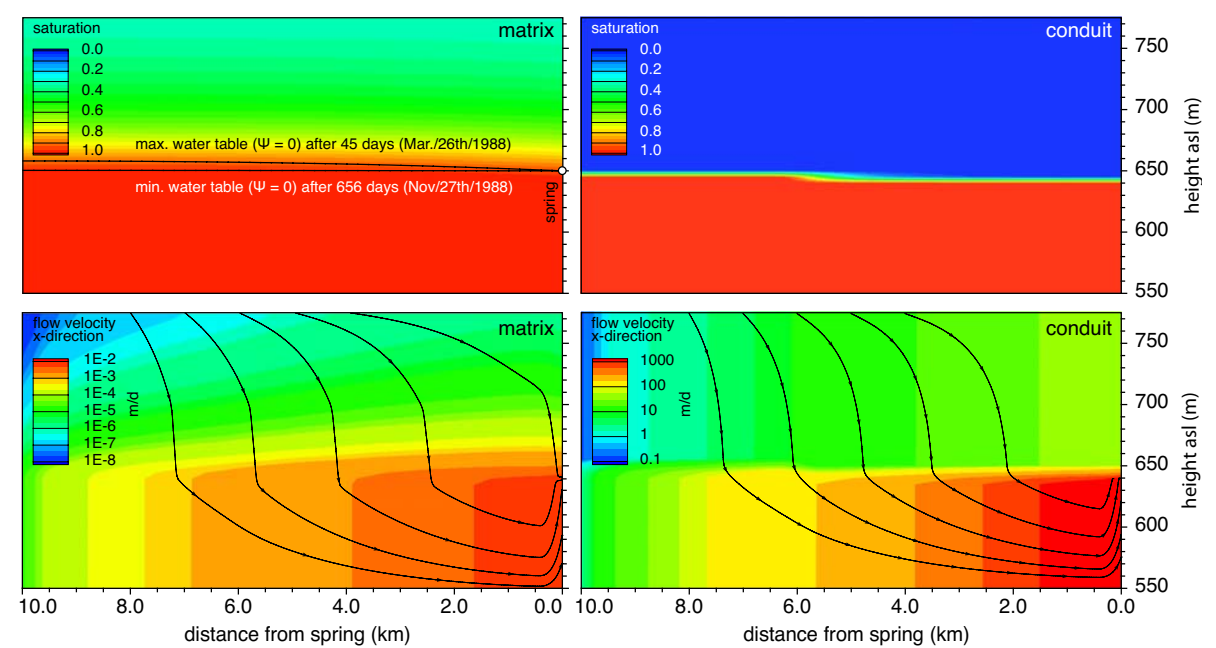

Fig. 5. Results of the transient flow model (26 March 1988). Shown water tables apply for both continua as the height is nearly equal and differs $1 \mathrm{~cm}$ at most. The van Genuchten parameter $\alpha_{\mathrm{m}}$ leads to a strong difference between the continua. The capillary rise is more pronounced in the matrix system, where saturation is ca. 0.35 near the surface. Saturation in the conduit system is lower than 0.1 above the water table and below 0.0001 near the surface. Flow velocities (only x-direction vector, note the different scaling for matrix and conduits) are apparently higher in the conduit continuum.

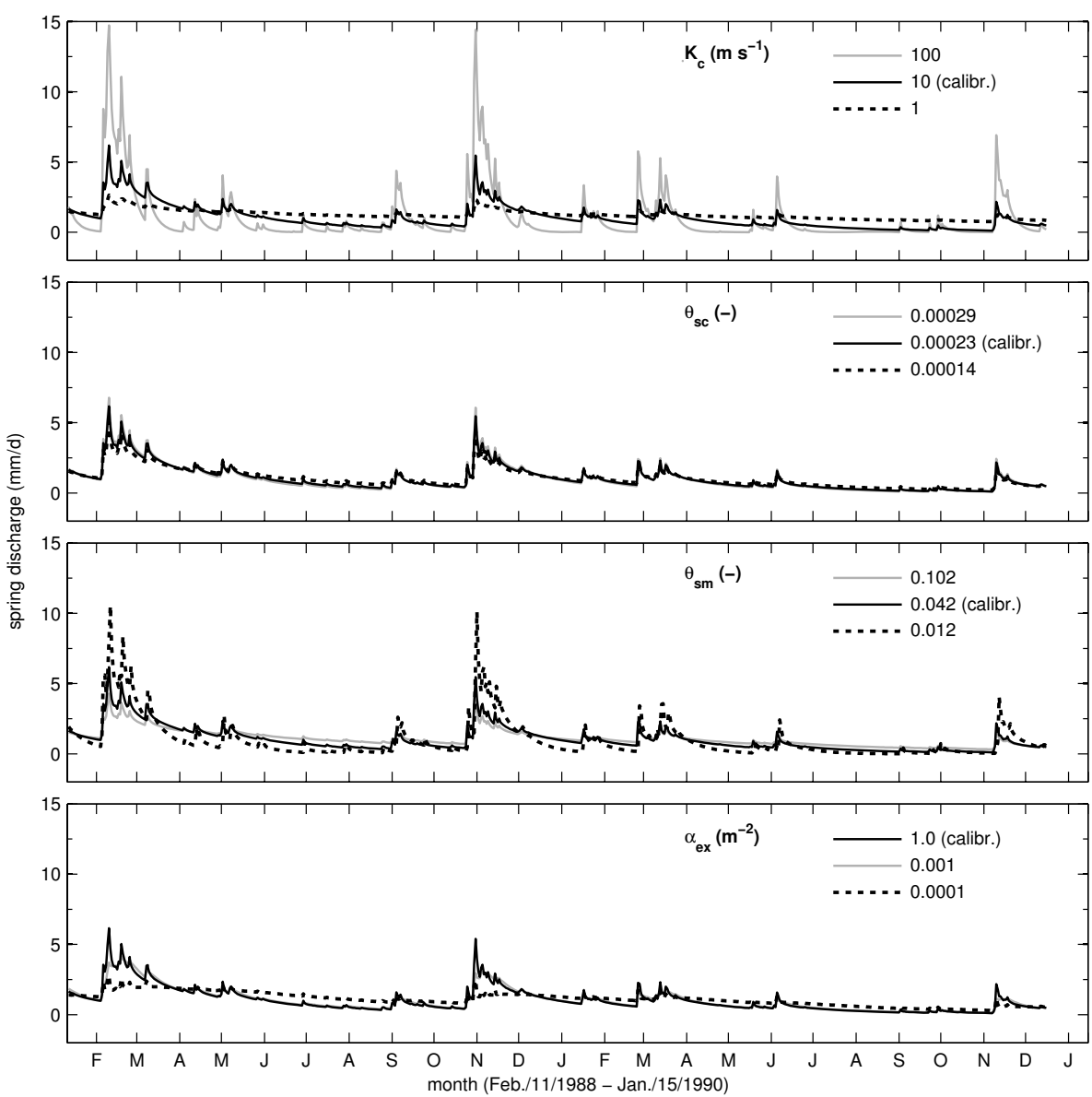

Fig. 6. Variation of hydraulic parameters $\left(K_{\mathrm{c}}, \theta_{\mathrm{sc}}, \theta_{\mathrm{sm}}\right)$ and the exchange parameter $\left(\alpha_{\mathrm{ex}}\right)$. 
Table 2. RMSE values and recession coeffcients for all sensitive parameters. Parameters with a maximum RMSE below $0.05 \mathrm{~mm} \mathrm{~d}^{-1}$ have been considered as insensitive. Subscript " $m$ " and " $c$ " denote the matrix resp. the conduit continuum. Bold numbers denote the calibrated value.

\begin{tabular}{|c|c|c|c|c|}
\hline \multirow[t]{2}{*}{ Parameter } & \multirow[t]{2}{*}{ Value } & \multicolumn{2}{|c|}{ Recess. coeff. (1/d) } & \multirow[t]{2}{*}{$\operatorname{RMSE}\left(\mathrm{mm} \mathrm{d}^{-1}\right)$} \\
\hline & & $\alpha_{1}$ & $\alpha_{2}$ & \\
\hline \multirow{3}{*}{$K_{\mathrm{c}}$} & 100 & 0.26 & 0.160 & 1.329 \\
\hline & 10 & 0.23 & 0.030 & - \\
\hline & 1 & 0.06 & 0.015 & 0.645 \\
\hline \multirow{3}{*}{$\theta_{\mathrm{sc}}$} & 0.00029 & 0.29 & 0.033 & 0.188 \\
\hline & 0.00023 & 0.23 & 0.030 & - \\
\hline & 0.00014 & 0.23 & 0.026 & 0.108 \\
\hline \multirow{3}{*}{$\theta_{\mathrm{sm}}$} & 0.102 & 0.33 & 0.066 & 0.318 \\
\hline & 0.042 & 0.23 & 0.030 & - \\
\hline & 0.012 & 0.19 & 0.023 & 0.317 \\
\hline \multirow{3}{*}{$\alpha_{\mathrm{ex}}$} & 1.0 & 0.23 & 0.033 & - \\
\hline & 0.001 & 0.06 & 0.030 & 0.231 \\
\hline & 0.0001 & 0.36 & 0.002 & 0.555 \\
\hline \multirow{3}{*}{$\alpha_{\mathrm{m}}$} & 0.365 & 0.28 & 0.025 & 0.329 \\
\hline & 0.0365 & 0.23 & 0.030 & - \\
\hline & 0.00365 & 0.36 & 0.122 & 1.285 \\
\hline \multirow{3}{*}{$n_{\mathrm{m}}$} & 2.23 & 0.31 & 0.029 & 0.064 \\
\hline & 1.83 & 0.23 & 0.300 & - \\
\hline & 1.23 & 0.26 & 0.049 & 0.563 \\
\hline \multirow{3}{*}{$S_{\mathrm{wrm}}$} & 0.6 & 0.29 & 0.050 & 0.54 \\
\hline & 0.3 & 0.32 & 0.034 & 0.142 \\
\hline & 0.05 & 0.23 & 0.030 & - \\
\hline \multirow{3}{*}{$k_{\text {rminc }}$} & 0.8 & 0.32 & 0.040 & 0.334 \\
\hline & 0.05 & 0.23 & 0.030 & - \\
\hline & 0.01 & 0.16 & 0.031 & 0.068 \\
\hline
\end{tabular}

gradient between matrix and conduits. The conduit porosity $\theta_{\mathrm{sc}}$ follows a similar pattern, i.e. an increase will enhance the exchange process, however, the impact on the discharge curves is far less pronounced within the given ranges and both recession coefficients are all in the same order of magnitude indicating a conduit dominated recession. A contrasting behavior is observed by a variation in matrix porosity $\theta_{\mathrm{sm}}$. With an increase in the parameter the water transfer between the continua during recharge events is decreased because of the lower head difference between conduit and matrix and the discharge curve is smoothened accordingly (see Fig. 6). The recession coefficient $\alpha_{1}$ and $\alpha_{2}$ are consequently slightly lower while for a very low matrix porosity of $1.2 \%$ it is apparent that recessions coefficients represent a strongly conduit dominated system $\alpha_{1}=0.33$ and $\alpha_{2}=0.066$. $K_{\mathrm{m}}$ displays a low sensitivity within the given parameter range which can be attributed to the high exchange parameter of the calibrated model of $\alpha_{\mathrm{ex}}=1.0$. The high value leads to an immediate equalization of heads between conduit and matrix such that water will not be restrained within the matrix system when total heads are slightly higher than within the conduit system. The matrix system always depends on the hydraulic state of the conduit continuum, which discharges water rapidly to the spring. However, in a three-dimensional karst system, flow velocities within the matrix will be little influenced by the conduit system with increasing distance to the conduit. The exchange parameter $\alpha_{\mathrm{ex}}$ is sensitive only for strong reductions on the order of three to four magnitudes. A reduction to 0.001 lowers the peak height of both main peaks while decreasing recession curve slopes $\alpha_{1}$ to 0.06 and slightly increasing base levels. Further reduction to 0.0001 drastically decreases peak heights and increases the base levels. The resulting $\alpha_{2}$ coeffcients are very low (0.002) and recharge events show no more pronounced peaks. An exchange reduction to 0.1 or 0.01 has no significant influence on the discharge curves, which indicates a sensitive interval between 0.001 and 0.0001 .

\subsection{Single variation of unsaturated zone parameters}

Variations of the sensitive van Genuchten parameters for the vadose zone are shown in Fig. 8 and the corresponding recession coefficients in Fig. 9. The decrease of $\alpha_{\mathrm{m}}$ and $n_{\mathrm{m}}$ results in a strong rise of peak heights and increase of recession slopes $\left(\alpha_{1}=0.36\right.$ and 0.26 respectively). The influence of the van Genuchten $\alpha_{\mathrm{m}}$ parameter on the discharge curve is connected to the inter-continuum water exchange process. Lowering the parameter increases the capillary rise, i.e. the matrix has higher saturation (and relative permeability) above the water table. Consequently the increased permeability leads to a stronger and earlier exchange of water from the matrix into the conduit continuum, such that recharge events affect spring discharge a lot earlier (pronounced event peaks). The opposite can be observed for a value of 0.365 where the saturation fringe declines very quickly with lower saturations above the water table. This reduces the main exchange interface to a smaller area above the water table. Thus during high recharge events, peak heights are reduced since water will remain longer in the matrix continuum and the $\alpha_{2}$ recession coefficient becomes slightly lower (0.025) reflecting the delayed discharge via the conduit system. The van Genuchten parameter $n_{\mathrm{m}}$ can be considered insensitive compared to $\alpha_{\mathrm{m}}$. The conduit van Genuchten parameters $\alpha_{\mathrm{c}}$ and $n_{\mathrm{c}}$ are as well insensitive for the shown simulations. In the range of chosen values, the conduits do not produce a strong capillary rise, i.e. the unsaturated zone above the conduit water table always displays a sharp transition from saturated to strongly unsaturated. As mentioned earlier the application of the van Genuchten parameters to a highly conductive and discrete flow system such as a conduit implies a general abstraction of the physically based van Genuchten parameter set in order to create an upscaled continuum system with a characteristic infiltration behavior and travel time distribution as well as 


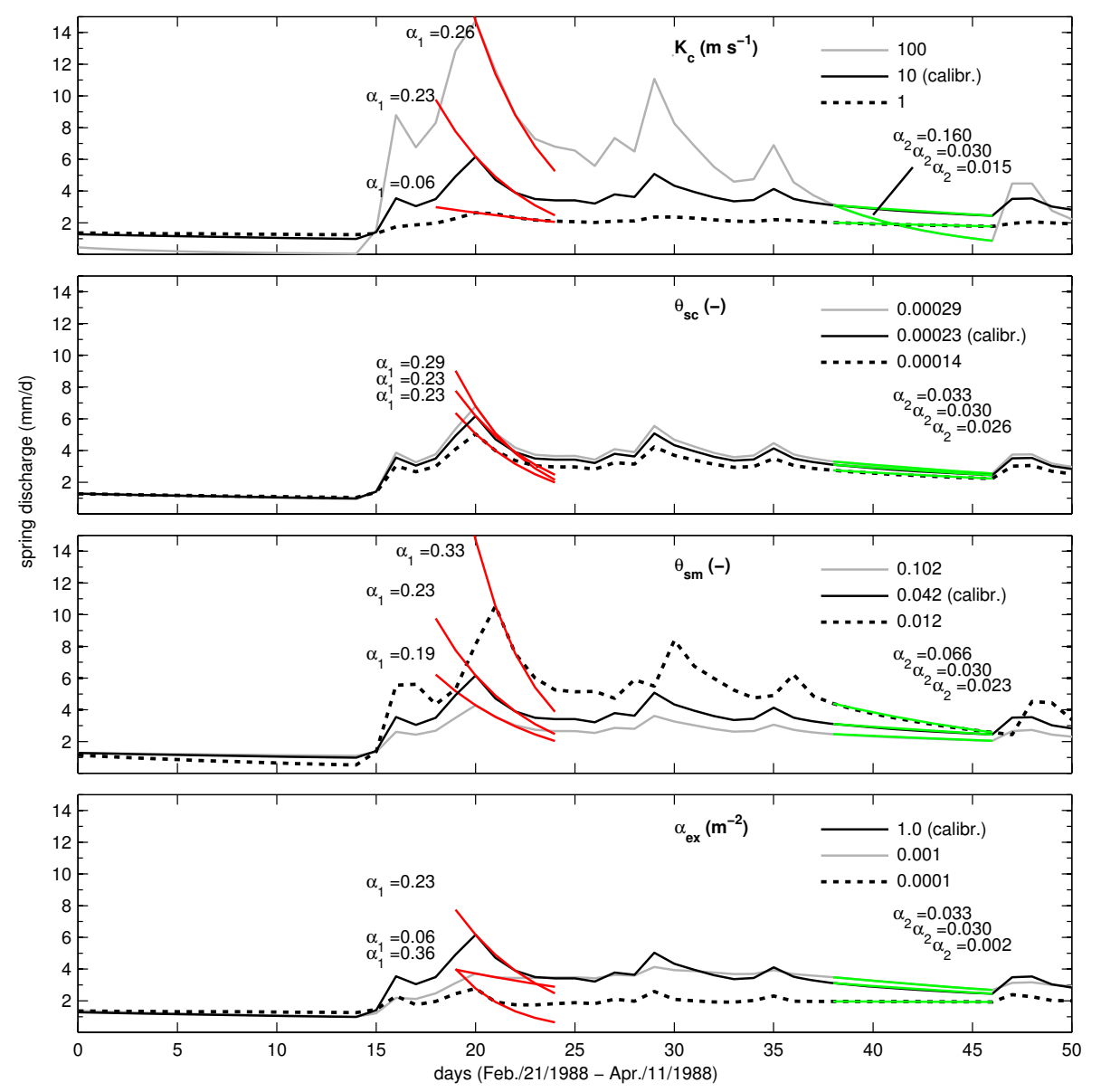

Fig. 7. Variation of hydraulic parameters $\left(K_{\mathrm{c}}, \theta_{\mathrm{sc}}, \theta_{\mathrm{sm}}\right)$ and the exchange parameter $\left(\alpha_{\mathrm{ex}}\right)$.

an exchange interface in the unsaturated zone. In this work the exchange process in the unsaturated zone can be controlled by the $\alpha_{\mathrm{c}}$ parameter in order to increase the capillary rise in the conduit continuum and enhance inter-continuum water transfer. However, such an approach also introduces a spatial information (i.e. the thickness of the conduit capillary fringe in vertical direction) which is not known in real karst systems. As described before the $k_{\text {rminc }}$ parameter is used instead to maintain a constant water exchange in the unsaturated zone independent of the hydraulic state of the conduit system if saturations are too low. The residual water saturation of the matrix $S_{\mathrm{wrm}}$ and the minimum relative permeability of the conduits $k_{\text {rminc }}$ both show a similar behavior regarding parameter variations. Increasing the parameters yields an enhanced exchange from the matrix to the conduit continuum due to a higher relative conductivity. Consequently, recharge events are transmitted faster to the model outlet, i.e. the spring.

\subsection{Combined parameter variations}

The above presented sensitivity analyzes imply only one single parameter varied at a time. However, a further important observation is that certain parameter combinations may show non-linear behavior with respect to their sensitivity, i.e. the influence of one parameter on the RMSE is not linear over the whole range of a second parameter. Table 3 shows maximum RMSE obtained for each parameter combination and if a non-linear relationship can be observed (bold RMSE values). For example, the simultaneous variation of the matrix van Genuchten parameter $\alpha_{\mathrm{m}}$ and the conduit conductivity $K_{\mathrm{c}}$ displays a pronounced sensitivity for low $\alpha_{\mathrm{m}}$ values (Fig. 10). While for the calibrated $\alpha_{\mathrm{m}}$ value of $0.0365 \mathrm{~m}^{-1}$, the conduit conductivity $K_{\mathrm{c}}$ is almost insensitive in the range of $1-10 \mathrm{~m} \mathrm{~s}^{-1}$; a lower $\alpha_{\mathrm{m}}$ value of $0.00365 \mathrm{~m}^{-1}$ yields a high RMSE of $1.6 \mathrm{~mm} \mathrm{~d}^{-1}$ already at a $K_{\mathrm{c}}$ value of $10 \mathrm{~m} \mathrm{~s}^{-1}$, i.e. $\partial \operatorname{RMSE}\left(\alpha_{\mathrm{m}}=0.00365\right) / \partial K_{\mathrm{c}}$ is much higher. A similar behavior can be shown for a combination of matrix porosity $\theta_{\text {sm }}$ and the conduit conductivity where lower porosities yield higher RMSE values with an increase in conduit conductivity to $100 \mathrm{~m} \mathrm{~s}^{-1}$, whereas for rather high matrix porosities of 0.102 the increase in RMSE is less pronounced. The conduit conductivity $K_{\mathrm{c}}$ exhibits a higher sensitivity for the calibrated exchange parameter $\alpha_{\mathrm{ex}}=1.0$ (see Fig. 10) such that a high conductivity value $\left(100 \mathrm{~m} \mathrm{~s}^{-1}\right)$ results in RMSE values 

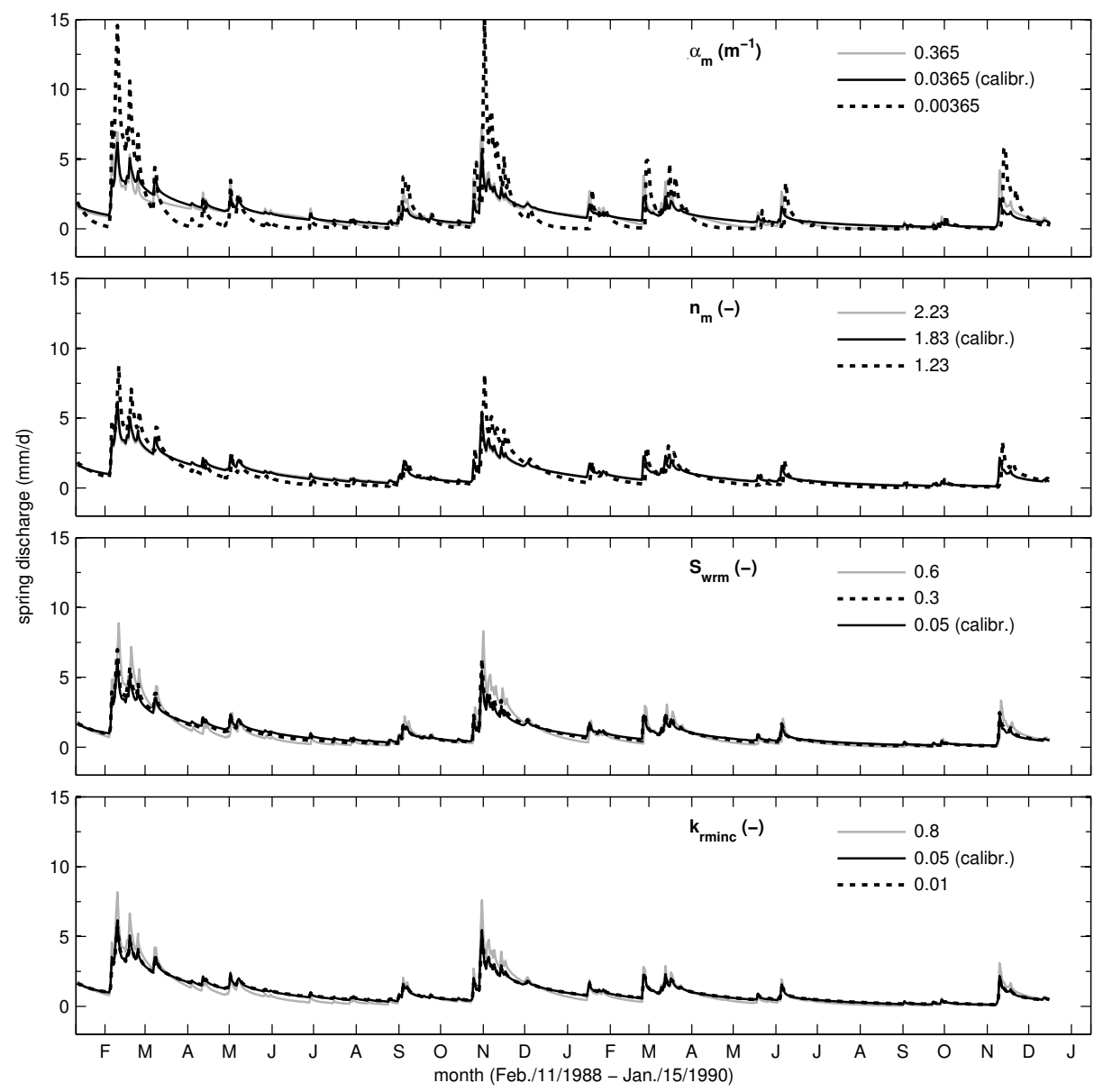

Fig. 8. Variation of the van Genuchten parameters $\left(\alpha_{\mathrm{m}}, n_{\mathrm{m}}, S_{\mathrm{wrm}}, k_{\mathrm{rminc}}\right)$.

Table 3. Parameter combinations used for the sensitivity analyzes and highest RMSE $\left(\mathrm{mm} \mathrm{d}^{-1}\right)$ observed. Bold RMSE values denote a non-linear inter-parameter dependence.

\begin{tabular}{lrrrllllllllllll}
\hline & \multicolumn{2}{c}{ Range } & & & & & & & & & & & & & \\
& Low & High & $K_{\mathrm{c}}$ & $K_{\mathrm{m}}$ & $\theta_{\mathrm{sc}}$ & $\theta_{\mathrm{sm}}$ & $\alpha_{\mathrm{ex}}$ & $Q$ & $\alpha_{\mathrm{m}}$ & $n_{\mathrm{m}}$ & $S_{\mathrm{wrm}}$ & $\alpha_{\mathrm{c}}$ & $n_{\mathrm{c}}$ & $S_{\text {wrc }}$ & $k_{\mathrm{rminc}}$ \\
\hline$K_{\mathrm{c}}$ & 1.0 & 100.0 & - & & & & & & & & & & & \\
$K_{\mathrm{m}}$ & $2.89 \times 10^{-7}$ & $2.89 \times 10^{-4}$ & 1.34 & - & & & & & & & & & & \\
$\theta_{\mathrm{sc}}$ & $1.40 \times 10^{-4}$ & $2.90 \times 10^{-4}$ & 1.48 & 0.19 & - & & & & & & & & & \\
$\theta_{\mathrm{sm}}$ & 0.02 & 0.102 & $\mathbf{2 . 2 3}$ & 0.83 & 0.89 & - & & & & & & & & \\
$\alpha_{\mathrm{ex}}$ & $1.00 \times 10^{-4}$ & 1.0 & $\mathbf{1 . 3 3}$ & 0.56 & 0.61 & $\mathbf{0 . 7 7}$ & - & & & & & & & \\
$Q$ & 30 & 95 & 1.33 & 0.06 & 0.23 & 0.77 & 0.57 & - & & & & & & \\
$\alpha_{\mathrm{m}}$ & $0.365 \times 10^{-3}$ & 3.65 & $\mathbf{3 . 2 0}$ & $\cdots$ & $\cdots$ & $\cdots$ & 1.29 & $\cdots$ & - & & & & & \\
$n_{\mathrm{m}}$ & 1.23 & 2.23 & $\cdots$ & $\cdots$ & $\cdots$ & $\cdots$ & 0.58 & $\cdots$ & 1.58 & - & & & & \\
$S_{\mathrm{wrm}}$ & 0.05 & 0.6 & $\cdots$ & $\cdots$ & $\cdots$ & $\cdots$ & $\cdots$ & $\cdots$ & 1.87 & $\cdots$ & - & & & \\
$\alpha_{\mathrm{c}}$ & 3.1 & 8.1 & $\cdots$ & $\cdots$ & $\cdots$ & $\cdots$ & 0.56 & $\cdots$ & $\cdots$ & $\cdots$ & $\cdots$ & - & & \\
$n_{\mathrm{c}}$ & 2.16 & 3.16 & $\cdots$ & $\cdots$ & $\cdots$ & $\cdots$ & 0.56 & $\cdots$ & $\cdots$ & 0.56 & $\cdots$ & 0.25 & - & \\
$S_{\mathrm{wrc}}$ & 0.0 & 0.4 & $\cdots$ & $\cdots$ & $\cdots$ & $\cdots$ & 0.56 & $\cdots$ & $\cdots$ & $\cdots$ & $\cdots$ & 0.01 & $\cdots$ & - \\
$k_{\mathrm{rminc}}$ & 0.01 & 0.8 & $\cdots$ & $\cdots$ & $\cdots$ & $\cdots$ & 0.56 & $\cdots$ & $\cdots$ & $\cdots$ & $\cdots$ & 0.33 & $\cdots$ & $\cdots$ & - \\
\hline
\end{tabular}




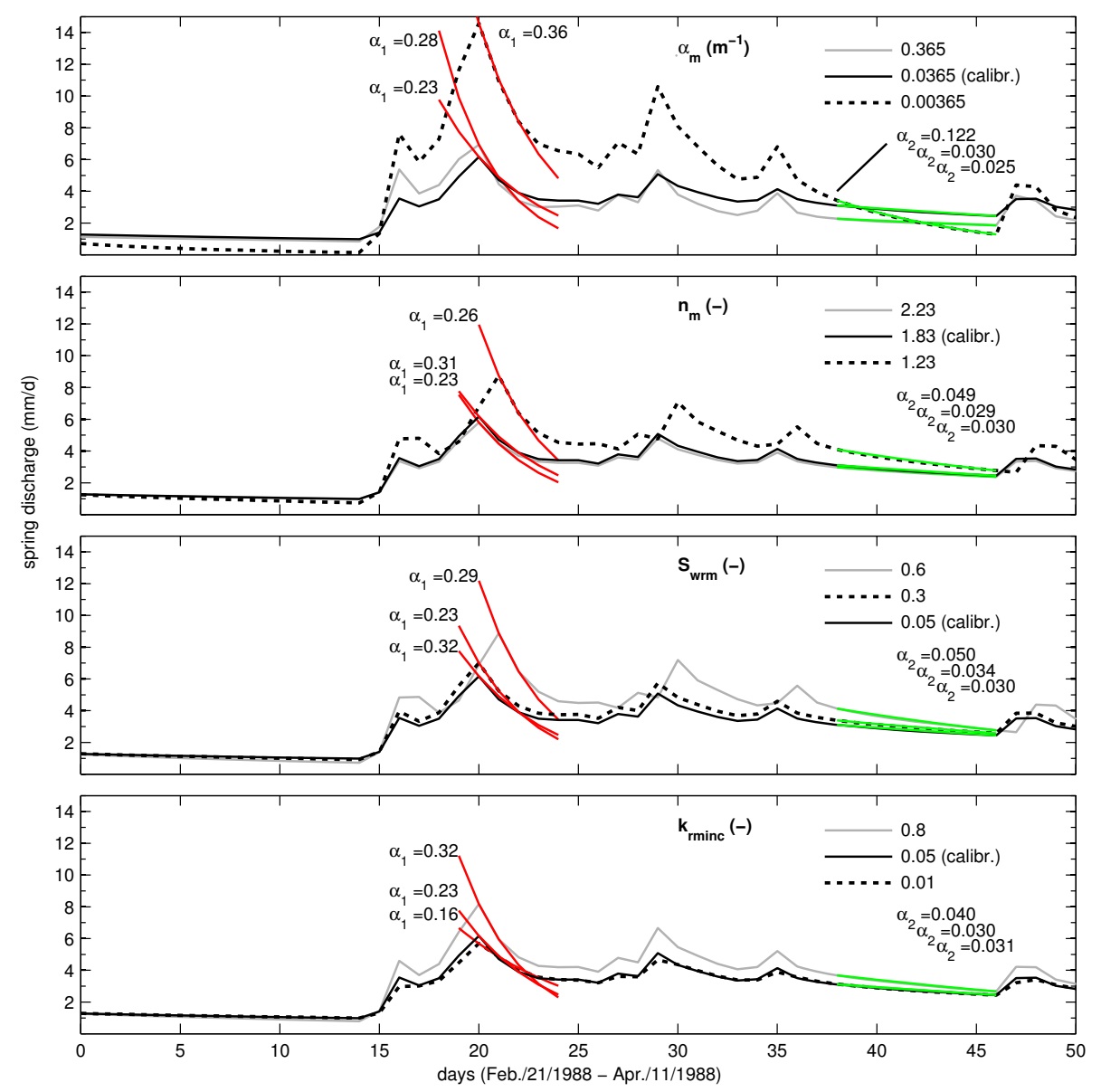

Fig. 9. Variation of the van Genuchten parameters $\left(\alpha_{\mathrm{m}}, n_{\mathrm{m}}, S_{\mathrm{wrm}}, k_{\mathrm{rminc}}\right)$.

of ca. $1.4 \mathrm{~mm} \mathrm{~d}^{-1}$ while for a lower exchange parameter the same conductivity yields a deviation of only $0.4 \mathrm{~mm} \mathrm{~d}^{-1}$. The exchange parameter has a higher sensitivity for high conductivity values of the conduit system, while it is nearly insensitive for low values $\left(1 \mathrm{~m} \mathrm{~s}^{-1}\right)$. In sum, the variation of the exchange parameter influences the discharge curve depending on the combination with other parameters. This behavior can also be observed for the combination of matrix porosity $\theta_{\text {sm }}$ and exchange parameter $\alpha_{\text {ex }}$. Here the exchange parameter has a higher sensitivity for matrix porosities between 0.032 and 0.102 , while at the lower limit $(0.012-0.022)$ this sensitivity vanishes.

\section{Conclusions}

The applied vertical two-dimensional double continuum approach is successfully employed to simulate the discharge behavior of the karst system Gallusquelle for a period of two years. Because of the high amount of model parameters of the saturated-unsaturated flow model, a comprehensive sensitivity analysis was performed. The analysis shows that the simulated discharge curve displays high sensitivity to a variation of a number of model parameters. The sensitivity study demonstrates that the simulation of karst hydraulics requires strong a-priori knowledge about parameter ranges to reduce ambiguity of the model. However, especially for the conduit continuum, only little about physical parameters is known and further research is needed. Physical parameters of the saturated fissured matrix can be obtained from field experiments on the scale of a representative elementary volume. Furthermore, the analysis shows that the sensitivity of a parameter depends to a large degree on the other calibrated model parameters. Therefore, sensitivity analyzes should simultaneously take into account parameters of both continua in order to detect deviations from a linear behavior if both parameters are sensitive. It also means that conclusions about parameter sensitivity change from model to model and are not simply transferable. The fissured matrix porosity as well as van Genuchten parameters of the matrix continuum are the most important parameters for an appropriate flow simulation. The conduit system drains the fissured matrix and can, due to its high hydraulic conductivity, effectively discharge varying quantities of water transferred from the matrix continuum. The van Genuchten parameters of the fissured matrix 

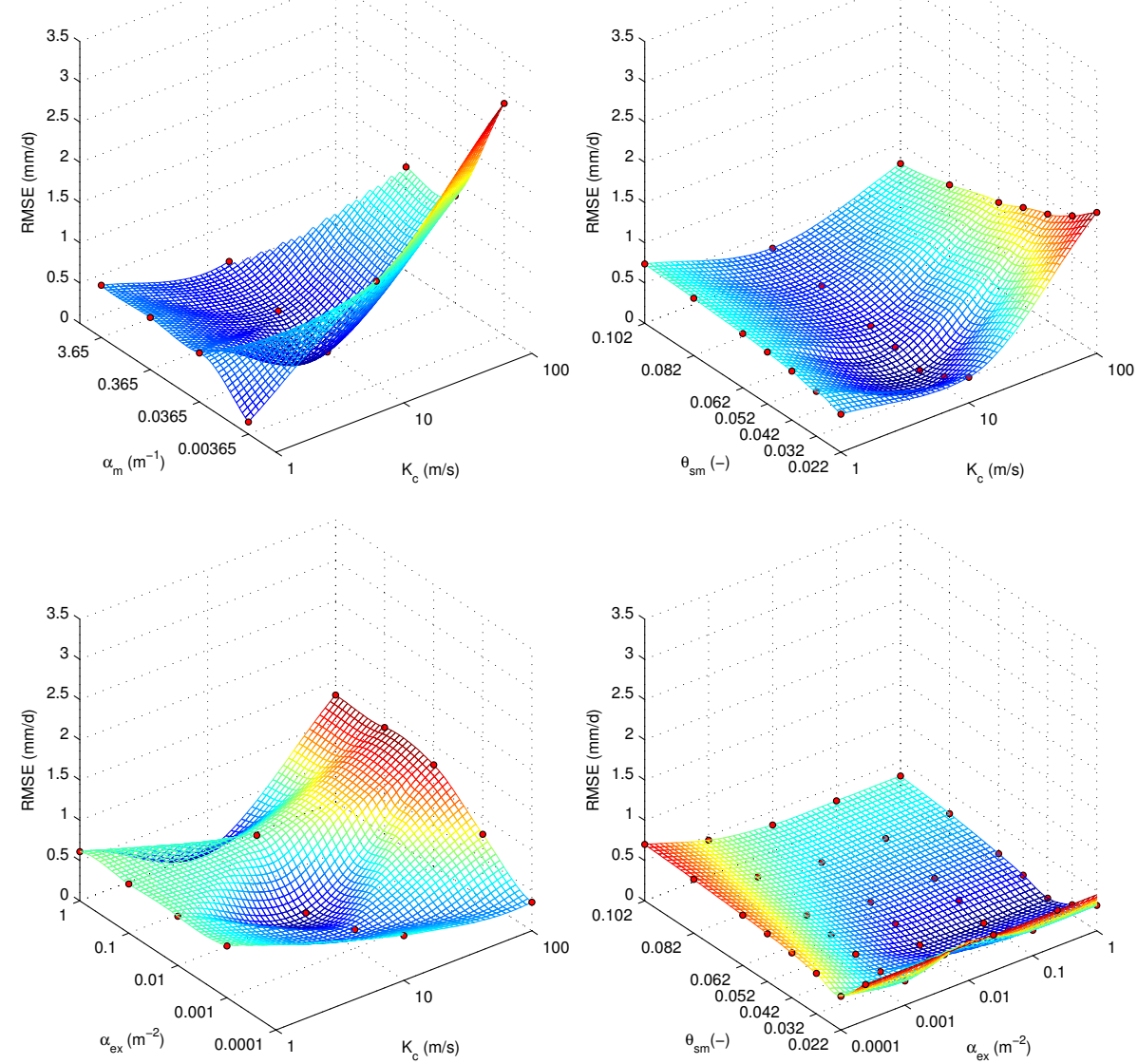

Fig. 10. Sensitivity matrices showing nonlinear inter-parameter dependencies.

are the most crucial property in terms of sensitivity, uncertainty and model limitations. The exchange process between matrix and conduit continuum is mainly controlled by differences in hydraulic properties. The $\alpha_{\text {ex }}$ parameter was set to a rather high value during the calibration, i.e. exchange is not limited by a too low exchange coefficient. According to Gerke and Van Genuchten (1993), the parameter is defined to express the interface connectivity on a rather small scale, e.g. between a porous medium and macropores. On catchment scale it might implicitly correspond to the type of karst system (i.e. karstified layers vs. karst conduits). The choice of a two-dimensional dual-continuum model for simulation of flow in karst systems leads to certain advantages and limitations. Considering the lack of information for most karst spring catchments the dual-continuum approach provides an efficient way to lump its geometrical features, i.e. only limited informations about the conduit geometry and rapid recharge area are necessary. However, lateral flow dynamics between the localized conduits and the matrix system are not considered and water table fluctuations in a continuum only represent the volume-averaged dynamics of the whole system. Vertical two-dimensional modeling ap- proaches are therefore more appropriate for the simulation of karstified layers than for the simulation of local karst conduit systems embedded in a fissured matrix. Furthermore the vertical two-dimensional approach neglects the lateral geometry of a spring catchment, e.g. reduction of cross-sectional area of the matrix contiunuum towards a karst spring, which might affect the discharge behavior.

The unified simulation of the saturated and unsaturated matrix and conduit continuum using the Richards equation is limited valid regarding the underlying physical process description. The application of the Richards equation for the matrix continuum can be considered as suitable at large scale (e.g. Kaufmann, 2003). But at this scale, van Genuchten parameters cannot be measured and become calibration parameters. A clear limitation is the loss of the physical meaning of the Richards equation for the conduit continuum. Flow through localized karst conduits might be highly transient, i.e. the application of open channel flow approaches would be appropriate (Reimann et al., 2011a). However, these approaches increase the number of calibration parameters and require additional knowledge about the geometry of a karst conduit system. Additionally, flow in unsaturated karst features (e.g. vertical shafts) is not controlled by matrix potential and capillary forces but rather flow processes dominated 
by gravitational forces such as film flow (Tokunaga and Wan, 1997; Tokunaga et al., 2000), turbulent film flow (Ghezzehei, 2004), droplet flow (Doe, 2001; Dragila and Weisbrod, 2004) and rivulet flow (Su et al., 2001; Dragila et al., 2004; $\mathrm{Su}$ et al., 2004). In order to be able to apply the vertical dual continuum approach, boundary conditions were modified and rapid recharge was directly injected at the bottom of the saturated conduit continuum. This abstraction clearly reduces the predictive capability of the applied approach.

Acknowledgements. This work was funded by the Deutsche Forschungsgemeinschaft (DFG; German Research Foundation) under grants no. GE 2173/2-2 and SA 501/24-1. Careful reviews of the manuscript by the editor and two anonymous reviewers are gratefully acknowledged. We would also like to thank Thomas Graf and Rob McLaren for their advice.

Edited by: I. Neuweiler

\section{References}

Abel, T., Sauter, M., and Hinderer, M.: Karst genesis of the Swabian Alb, south Germany, since the Pliocene, Acta Geol. Pol., 52, 4354, 2002.

Bamberg, G., Baur, F., and Krapp, M.: Statistik, Oldenbourg, München, 2007.

Barenblatt, G. I., Zheltov, I. P., and Kochina, I. N.: Basic Concepts in the Theory of Seepage of Homogenous Liquids in Fissured Rocks Strata, J. Appl. Math. Mech., 24, 1286-1303, 1960.

Birk, S., Geyer, T., Liedl, R., and Sauter, M.: Process-Based Interpretation of Tracer Tests in Carbonate Aquifers, Ground Water, 43, 381-388, 2005.

Birk, S., Liedl, R., and Sauter, M.: Karst spring responses examined by process-based modeling., Ground Water, 44, 832-836, 2006.

Brouyère, S.: Modelling the migration of contaminants through variably saturated dual-porosity, dual-permeability chalk, J. Contam. Hydrol., 82, 195-219, 2006.

Contractor, D. N. and Jenson, J. W.: Simulated effect of vadose infiltration on water levels in the Northern Guam Lens Aquifer, J. Hydrol., 229, 232-254, 2000.

Doe, T.: What do drops do? Surface wetting and network geometry effects on vadose-zone fracture flow, in: Conceptual models of flow and transport in the fractured vadose zone, Chap. 8, 243270, National Academy Press, Washington D.C., 2001.

Dragila, M. I. and Weisbrod, N.: Flow in Menisci Corners of Capillary Rivulets, Vadose Zone J., 3, 1439-1442, 2004.

Dragila, M. I., Weisbrod, N., and Council, N. R.: Fluid motion through an unsaturated fracture junction, Water Resour. Res., 40, 1-11, 2004.

Dreiss, S. J.: Regional scale transport in a karst aquifer: 1. Component separation of spring flow hydrographs, Water Resour. Res., 25, 117-125, 1989.

Dreybrodt, W., Gabrovšek, F., and Romanov, D.: Processes of Speleogenessis: A Modeling Approach, Karst Research Institute at ZRC SAZU, ZRC Publishing, Ljubljana, 2005.

Durner, W.: Hydraulic conductivity estimation for soils with heterogeneous pore structure, Water Resour. Res., 30, 211, doi:10.1029/93WR02676, 1994.
Gerke, H. and Van Genuchten, M.: Evaluation of a First-Order Water Transfer Term for Variably Saturated Dual-Porosity Flow Models, Water Resour. Res., 29, 1225-1238, 1993.

Germann, P. F., Helbling, A., and Vadilonga, T.: Rivulet Approach to Rates of Preferential Infiltration, Vadose Zone J., 6, 207-220, 2007.

Geyer, T.: Process-based characterisation of flow and transport in karst aquifers at catchment scale, Ph.D. thesis, University of Göttingen, 2008.

Geyer, T., Birk, S., Liedl, R., and Sauter, M.: Quantification of temporal distribution of recharge in karst systems from spring hydrographs, J. Hydrol., 348, 452-463, 2008.

Ghezzehei, T. A.: Constraints for flow regimes on smooth fracture surfaces, Water Resour. Res., 40, 1-14, 2004.

Gwinner, M. P.: Origin of the Upper Jurassic limestones of the Swabian Alb (Southwest Germany), E. Schweizerbart, 1976.

Hill, C. and Polyak, V.: Karst hydrology of Grand Canyon, Arizona, USA, J. Hydrol., 390, 169-181, 2010.

Jeannin, P. Y.: Modeling flow in phreatic and epiphreatic karst conduits, Water Resour. Res., 37, 191-200, 2001.

Kaufmann, G.: Modelling unsaturated ow in an evolving karst aquifer, J. Hydrol., 276, 53-70, doi:10.1016/S00221694(03)00037-4, 2003.

Mclaren, R. G., Forsyth, P. A., Sudicky, E. A., Vanderkwaak, J. E., Schwartz, F. W., and Kessler, J. H.: Flow and transport in fractured tuff at Yucca Mountain: numerical experiments on fast preferential flow mechanisms, J. Contam. Hydrol., 43, 211-238, 2000.

Mualem, Y.: A new model for predicting the hydraulic conductivity of unsaturated porous media, Water Resour. Res., 12, 513-522, 1976.

Reimann, T., Geyer, T., Shoemaker, W. B., Liedl, R., and Sauter, M.: Effects of dynamically variable saturation and matrix-conduit coupling of flow in karst aquifers, Water Resour. Res., 47, 1-19, 2011a.

Reimann, T., Rehrl, C., Shoemaker, W. B., Geyer, T., and Birk, S.: The significance of turbulent flow representation in singlecontinuum models, Water Resour. Res., 47, 1-15, 2011 b.

Richards, L. A.: Capillary Conduction of Liquids Through Porous Mediums, Physics, 1, 318-333, 1931.

Rosenbom, A., Therrien, R., and Refsgaard, J.: Numerical analysis of water and solute transport in variably-saturated fractured clayey till, J. Contam. Hydrol., 104, 137-152, 2009.

Ross, P. J. and Smettem, K. R. J.: Describing soil hydraulic properties with sums of simple functions, Soil Sci. Soc. Am. J., 57, 26-26, 1993.

Roulier, S., Baran, N., Mouvet, C., Stenemo, F., Morvan, X., Albrechtsen, H.-J. R., Clausen, L., and Jarvis, N.: Controls on atrazine leaching through a soil-unsaturated fractured limestone sequence at Brévilles, France, J. Contam. Hydrol., 84, 81-105, 2006.

Sauter, M.: Quantification and Forecasting of Regional Groundwater Flow and Transport in a Karst Aquifer (Gallusquelle, Malm, SW. Germany), Tübinger Geowissenschaftliche Arbeiten, 1992.

Sauter, M.: Differentiation of flow components in a karst aquifer using the $\delta^{18} \mathrm{O}$ signature, in: Tracer Hydrology, edited by: Kranjc, A., 435-441, Balkema, 1997.

Sauter, M., Geyer, T., Kovacs, A., and Teutsch, G.: Modellierung der Hydraulik von Karstgrundwasserleitern - Eine Übersicht, 
Grundwasser, 3, 143-156, 2006.

Schwartz, F., Sudicky, E., and McLaren, R.: Ambiguous hydraulic heads and $C^{14}$ activities in transient regional flow, Ground Water, 48, 366-379, 2010.

Smart, P. L. and Hobbs, S. L.: Characterisation of carbonate aquifers: A conceptual base, in: Proceedings of the Environmental Problems in Karst Terranes and Their Solutions Conference, Bowling Green, Ky. Published by NWWA, 17-31, 1986.

Su, G. W., Geller, J. T., Pruess, K., and Hunt, J. R.: Solute transport along preferential flow paths in unsaturated fractures, Water Resour. Res., 37, 2481-2491, 2001.

Su, G. W., Geller, J. T., Hunt, J. R., and Pruess, K.: Small-Scale Features of Gravity-Driven Flow in Unsaturated Fractures, Vadose Zone J., 3, 592-601, 2004.

Teutsch, G.: Grundwassermodelle im Karst: Praktische Ansätze am Beispiel zweier Einzugsgebiete im Tiefen und Seichten Malmkarst der Schwäbischen Alb, Ph.D. thesis, Universität Tübingen, 1988.

Teutsch, G. and Sauter, M.: Groundwater modeling in karst terranes: Scale effects, data acquisition and field validation, in: Proc. Third Conf. Hydrogeology, Ecology, Monitoring, and Management of Ground Water in Karst Terranes, Nashville, TN, 17-35, 1991.
Therrien, R. and Sudicky, E. A.: Three-dimensional analysis of variably-saturated flow and solute transport in discretelyfractured porous media, J. Contam. Hydrol., 3542, 1-44, 1996.

Therrien, R., McLaren, R., Sudicky, E., and Panday, S.: HydroGeoSphere: A three-dimensional numerical model describing fullyintegrated subsurface and surface flow and solute transport, Manual (Draft), HydroGeoLogic Inc., Herndon, VA, 2006.

Tokunaga, T. K. and Wan, J.: Water film flow along fracture surfaces of porous rock, Water Resour. Res., 33, 1287, doi:10.1029/97WR00473, 1997.

Tokunaga, T. K., Wan, J., and Sutton, S. R.: Transient film flow on rough fracture surfaces, Water Resour. Res., 36, 1737-1746, 2000.

van Genuchten, M. T.: A Closed-form Equation for Predicting the Hydraulic Conductivity of Unsaturated Soils, Soil Sci. Soc. Am. J., 44, 892-898, 1980.

Weiss, E. G.: Porositäten, Permeabilitäten und Verkarstungserscheinungen im mittleren und oberen Malm der südlichen Frankenalb, Ph.D. thesis, Universität Erlangen, 1987. 